\title{
Metabolism Disaster in Polytrauma Patients
}

\author{
Alexandru Florin Rogobete1,2, Ovidiu Horea Bedreag ${ }^{1,2}$ \\ 1 Faculty of Medicine, "Victor Babeș” University of Medicine and Pharmacy, Timișoara, Romania \\ 2 Clinic of Anesthesia and Intensive Care, "Pius Brinzeu" Emergency County Hospital, Timișoara, Romania
}

\section{CORRESPONDENCE}

Alexandru Florin Rogobete

P-ța Eftimie Murgu nr. 2

300041 Timișoara, Romania

Tel: +40 256204400

E-mail: alexandru.rogobete@umft.ro

\section{ARTICLE HISTORY}

Received: 29 November, 2016

Accepted: 3 December, 2016
The critical polytrauma patient presents a series of secondary pathophysiological traumatic injuries that contribute to a poor outcome. The most common are systemic inflammatory response syndrome (SIRS), sepsis, acute respiratory distress syndrome (ARDS), and oxidative stress (OS).1,2 Another important aspect that contributes significantly to the worsening of the clinical features of these patients is represented by their metabolic status. ${ }^{3}$ Recent studies have highlighted a number of statistically significant correlations between underfeeding, overfeeding and increased time during mechanical ventilation, increased standing time in the intensive care unit (ICU), and increased rate of mortality. Alberda et al. reported a study on the relationship between metabolic status and the outcome of critical patients, with a mortality reduction in patients whose nutrition therapy was optimized. ${ }^{4}$

Adapting the nutrition of critically ill patients is often a challenge because the equations used to predict energy demand show significant errors. Thus, a number of complications can occur that are directly related to other associated pathophysiology, such as overfeeding, underfeeding, re-feeding and autophagy. Kross et al. conducted a study on the predictive accuracy of energy expenditure (EE) in critical, mechanically ventilated patients for a number of predictive equations such as the Harris-Benedict, Owen, Mifflin, and Ireton-Jones. In the study, they showed that none of the equations were correct in predicting EE. ${ }^{5}$ In a study regarding the type of nutrition administered to critical patients, Rugeles et al. showed that there was no difference in statistical terms between hyperproteic $(1.7 \mathrm{~g} / \mathrm{kg} /$ day), hypocaloric $(15 \mathrm{kcal} / \mathrm{kg} /$ day $)$ and normocaloric hyperproteic $(25 \mathrm{kcal} / \mathrm{kg} /$ day $)$ nutrition. ${ }^{6}$

Sepsis occurs in a high percentage of critical polytrauma patients. ${ }^{7}$ Recent studies have shown a significant increase in the incidence of sepsis in malnourished patients. Moreover, the critically ill patient with sepsis is characterized by a specific hypermetabolism. Feferbaum et al. studied the expression of EE in patients with sepsis, highlighting a progressive increase in the acute phase, reaching $68.3 \pm 10.9 \mathrm{kcal} / \mathrm{kg} /$ day. $^{8}$

Another pathophysiology closely related to metabolic imbalances is OS. Numerous studies have reported the implications of free radicals (FR) on metabolic and biochemical mechanisms. From a biochemical point of view, FR show increased reactivity toward biomacromolecules in the human body, being ubiq- 
uitous products. The most important representatives are the hydroxyl radical $\left(\mathrm{HO}^{-}\right)$, the superoxide radical $\left(\mathrm{O}^{2-}\right)$, hydrogen peroxide $\left(\mathrm{H}_{2} \mathrm{O}_{2}\right)$, nitric oxide $(\mathrm{NO})$, and the peroxynitrite radical $\left(\mathrm{ONOO}^{-}\right)$. Moreover, due to the increased concentrations of FR, the antioxidant/oxidant balance is altered, the pro-oxidative status is significantly augmented and the lipid, protein and glucidic systems are affected. Thus, an altered metabolic status appears, where the energy generating capacity of the cells is impaired and the body enters into an energetic collapse. Bedreag et al., in a study on the impact of OS on the outcome of critically ill polytrauma patients, revealed a significant reduction in both biochemical-humoral values and mortality rate in patients whose OS was minimized by administering substances with powerful antioxidant capacity. ${ }^{9}$

Moreover, several studies highlighted a number of genetic implications regarding the biochemical mechanisms of a critical patient's metabolism. Lu et al. revealed the implication of microRNA-223 in the metabolic activity of insulin and glucose in cardiomyocytes due to the modulation activity of glucose transporter 4 (GLUT4). ${ }^{10}$

Regarding monitoring methods, one of the most discussed is indirect calorimetry (IC). In this case, EE prediction is done by continuously monitoring oxygen consumption $\left(\mathrm{VO}_{2}\right)$ and carbon dioxide production $\left(\mathrm{VCO}_{2}\right)$, calculating the respiratory quotient (RQ) and EE. Kaen $e t$ al. conducted a study on EE in patients with sepsis/septic shock. To determine EE, they used IC with a mechanical ventilator, and reported an $\mathrm{EE}$ of $26.7 \pm 5.3 \mathrm{kcal} / \mathrm{kg} /$ day at 72 hours from the onset of septic shock. Moreover, the study reported significant differences between the EE measured by indirect calorimetry and the EE calculated with predictive equations. ${ }^{11}$

A high proportion of critical polytrauma patients require mechanical ventilation. Finding the optimum time to separate these patients from the ventilator can often be extremely difficult. Moreover, each extra day of mechanical ventilation involves a number of pathophysiological risks, but also a substantial increase in care costs. Recent studies have shown an increase of $\mathrm{VO}_{2}$ and $\mathrm{EE}$ when they tried weaning in improper conditions from a clinical point of view. The ventilation dependency of inadequately nourished patients can be explained by the administration of excess energy substrate, compelling the body to burn this substrate, increasing $\mathrm{VO}_{2}$ and $\mathrm{VCO}_{2}$. On the other hand, energy substrate deprivation is followed by burning the body's own resources, particularly muscle mass, increasing $\mathrm{VO}_{2}$ significantly. In both cases, both $\mathrm{VO}_{2}$ and $\mathrm{VCO}_{2}$ increase significantly in the detriment of the respiratory capacity of these patients, making it necessary to maintain the mechanical ventilator. Thus, through optimized nutrition and insuring the recovery of respiratory muscle function, faster weaning can be secured safely. Many studies on monitoring the metabolism in the process of weaning have shown the importance of optimizing nutritional therapy in this case. ${ }^{12-14}$

In conclusion, we can say that the evaluation and ongoing monitoring of the metabolic status of critically ill polytrauma patients is necessary because of the implications on the clinical outcome, and indirect calorimetry and gas exchange may bring considerable benefits. Last but not least, intensive care and nutritional optimization based on complex parameters have a significant contribution to the prognosis of these patients.

\section{REFERENCES}

1. Bedreag $\mathrm{OH}$, Rogobete $\mathrm{AF}$, Sărăndan $\mathrm{M}$, et al. Oxidative stress and antioxidant therapy in traumatic spinal cord injuries. Rom J Anesth Int Care. 2014;21:123-129.

2. Bar-or D, Bar-or R, Rael LT, Brody EN. Redox Biology Oxidative stress in severe acute illness. Redox Biol. 2015;4:340-345.

3. Naviaux RK. Metabolic features of the cell danger response. Mitochondrion. 2014;16:7-17

4. Alberda C, Gramlich L, Jones N, et al. The relationship between nutritional intake and clinical outcomes in critically ill patients: Results of an international multicenter observational study. Intensive Care Med. 2009;35:1728-1737.

5. Kross EK, Sena M, Rd KS, Stapleton RD. A comparison of predictive equations of energy expenditure and measured energy expenditure in critically ill patients. J Crit Care. 2012;27:321.e5-321.e12.

6. Rugeles S, Villarraga-Angulo LG, Ariza-Gutiérrez A, Chaverra-Kornerup S, Lasalvia P, Rosselli D. High-protein hypocaloric vs normocaloric enteral nutrition in critically ill patients: A randomized clinical trial. J Crit Care. 2016:35:110-114.

7. Adams CA. Sepsis biomarkers in polytrauma patients. Crit Care Clin. 2011;27:345-354

8. Feferbaum R, Leone C, Siqueira AA, et al. Rest energy expenditure is decreased during the acute as compared to the recovery phase of sepsis in newborns. Nutr Metab. 2010;7:63

9. Bedreag $\mathrm{OH}$, Rogobete AF, Sandesc D, et al. Modulation of the Redox Expression and Inflammation Response in the Critically III Polytrauma Patient with Thoracic Injury. Statistical Correlations between Antioxidant Therapy and Clinical Aspects. A Retrospective Single Center Study. Clin Lab. 2016:(10):1-13.

10. Lu H, Buchan RJ, Cook SA. MicroRNA-223 regulates Glut4 expression and cardiomyocyte glucose metabolism. Cardiovasc Res. 2010;86:410-420.

11. Kaen K, Kaen K, Unit CE, Kaen K, Hospital S. Energy expenditure in severe sepsis or septic shock patients: a Thai Medical Intensive Care Unit study. Asia Pacific Journal of Clinical Nutrition. 2016;(66):1-9.

12. Maclntyre N. Evidence-Based Guidelines for Weaning and Discontinuing Ventilatory Support - A Collective Task Force Facilitated by the American College of Chest Physicians. Chest J. 2001:120:375-395.

13. Bassili HR, Deitel M. Effect of Nutritional Support on Weaning Patients Off Mechanical Ventilators. J Parenter Enter Nutr. 1981;5:161-163.

14. Kavazis AN, Talbert EE, Smuder AJ, Hudson MB, Nelson WB, Powers SK. Mechanical ventilation induces diaphragmatic mitochondrial dysfunction and increased oxidant production. Free Radic Biol Med. 2009;46:842850. 